\title{
Video Promosi Program Acara Siaran Star Radio Tangerang
}

\author{
Adinda Apriliani Lase* ${ }^{* 1}$, Arif Marjuki ${ }^{2}$, Rizky Ramadhan ${ }^{3}$ \\ ${ }^{12}$ Program Studi Teknik Informatika, Fakultas Sains and Teknologi, Universitas Raharja \\ ${ }^{3}$ Program Studi Manajemen Informatika, Fakultas Sains and Teknologi, Universitas Raharja \\ Email: $*^{1}$ adinda.lase@ raharja.info ${ }^{2}$ arif.marjuki@ raharja.info, \\ rizky.ramadhan@raharja.info
}

\begin{abstract}
Abstrak
Media promosi sangat berpengaruh dalam strategi pemasaran untuk dapat meningkatkan daya Tarik masyarakat, media promosi dibutuhkan oleh stasiun radio seperti Star Radio yang berada dibawah naungan PT. Radio Suara Tunggal Angkasa Raya, yang terletak di Jalan Pulau Putri Raya, No. 2, Modernland Tangerang, Banten 15117. Permasalahan yang dihadapi Star Radio dalam mempromosikan program acara siaran baru, saat ini belum terdapat video promosi program untuk acara siaran baru tersebut. Sebelumnya Star Radio mempromosikannya hanya melalui informasi kegiatan dan acara talk show menggunakan youtube, informasi digital pada media sosial dan website secara sederhana yang berdampak banyak masyarakat yang belum mengetahui atau mengenal tentang acara siaran baru yang dimiliki oleh Star Radio. Maka diperlukan adanya media video promosi agar masyarakat dapat mengetahui program acara baru tersebut. Metode penelitiannya yaitu dengan pengumpulan data, analisa perancangan media dan konsep produksi media (KPM) yaitu: pre production, production, dan postproduction. Hasil dari penelitian ini berupa media video promosi program acara siaran Star Radio yang diharapkan dapat membantu masyarakat dapat mengetahui program acara yang sudah ada maupun yang baru pada Star Radio secara informatif.
\end{abstract}

Kata Kunci - Video Promosi, Informasi, Radio

\begin{abstract}
Media promotion is very influential in marketing strategies to increase public attractiveness, promotional media is needed by radio stations such as Star Radio which is under the auspices of PT. Radio Suara Tunggal Angkasa Raya, which is located on Jalan Pulau Putri Raya, No. 2, Modernland Tangerang, Banten 15117. The problems faced by Star Radio in promoting new broadcast programs, currently there is no program promotion video for this new broadcast program. Previously, Star Radio promoted it only through information on activities and talk shows using YouTube, digital information on social media and websites in a simple manner which resulted in many people who did not know or know about the new broadcast programs that Star Radio had. so there is a need for promotional video media so that the public can find out about the new program. The research method is data collection, analysis of media design and the concept of media production (KPM), namely: pre production, production, and postproduction. The results of this research are in the form of promotional video media for Radio Star broadcast programs which are expected to help the public to find out about existing and new programs on Star Radio in an informative manner.
\end{abstract}

Keywords - Promotion Video, Information, Radio 


\section{PENDAHULUAN}

Radio merupakan salah satu media komunikasi yang digunakan untuk menyampaikan pesan kepada para pendengar setianya, pada saat ini sudah banyak stasiun radio yang terbesar diseluruh dunia terutama di Indonesia yang sudah hampir menyebar di seluruh dunia ${ }^{[1]}$.

Stasiun Star Radio merupakan salah satu stasiun radio Tangerang yang berdiri sejak 11 Maret 1990. Star Radio ini berlokasi di Jalan Pulau Putri Raya, No. 2, Modernland Tangerang, Banten 15117.

Aliran frekuensi Star Radio yaitu 107.3 FM dan area jangkauan pemancar Star Radio Tangerang meliputi daerah Kota Tangerang dan sekitarnya, Tangerang Selatan dan sekitarnya, Ciledug, Bintaro, Serpong, Pamulang, BSD, Karawaci, Binong, Kelapa Dua, Cikupa, Balaraja, Cengkareng, dan daerah sekitarnya. Berdasarkan badan pusat statistik Kota Tangerang, jumlah penduduk pada tahun 2018 ini sebanyak 2.185.304 jiwa.

Permasalahan yang terdapat pada Star Radio yaitu, penyajian dalam media informasi dan promosi sebelumnya hanya terdapat informasi kegiatan dan acara talk show menggunakan youtube, informasi digital pada media sosial dan website secara sederhana. Saat ini Star Radio memiliki 2 program acara siaran baru yaitu Rising Star dan Portal Indonesia yang baru diluncurkan pada tahun 2019 dan belum memiliki video promosi mengenai program acara siaran di Star Radio, sehingga masih banyak masyarakat yang belum mengetahui atau mengenal program acara siaran tersebut.

Video promosi bertujuan untuk mempromosikan produk / jasa yang berisi tentang keunggulan dari produk / jasa tersebut. Biasanya iklan cenderung menggunakan sebuah tagline yang singkat dan bersifat persuasif sehingga mudah diingat ${ }^{[2]}$.

Untuk itu diperlukan adanya perancangan video promosi mengenai pengenalan program acara siaran yang ada di Star Radio, yang bertujuan untuk memperkenalkan latar belakang, visi dan misi, kegiatan, serta program acara siaran pada Star Radio, agar mudah diketahui dan dikenal oleh masyarakat dan lebih menarik secara visualisasi. Sehingga video promosi ini dapat menjadi solusi untuk pemecahan masalah pada media informasinya.

Tujuan dari pembuatan video promosi ini adalah Untuk menghasilkan video promosi pada Star Radio dengan konsep kreatif yang terdapat audio, visual, effect visual, sehingga dapat menarik audience yang menontonnya yang dapat meningkatkan jumlah pendengar pada setiap program acara siaran.

Melalui video promosi program acara siaran pada Star Radio ini, diharapkan dapat meningkatkan jumlah pendengar setiap tahunnya dan masyarakat dapat lebih mengenal dan mengetahui Star Radio.

\section{METODE PENELITIAN}

Metode yang digunakan dalam penelitian ini yaitu: (1) Metode Pengumpulan Data, metode ini digunakan dengan cara melakukan Observasi, wawancara dan Studi pustaka. (2) Video promosi pada Star Radio ini dirancang dengan menggunakan aplikasi program komputer grafis, yaitu Adobe Premiere Pro 2019, Adobe Photoshop, dan Adobe Audition CC 2017. (3) Konsep Produksi Media (KPM) terdiri dari: Pre Production, Production dan Post Production.

\section{Literature Review}

Berikut adalah beberapa penelitian yang berkaitan dengan media video Promosi ini yaitu:

1. Penelitian yang dilakukan oleh Suci, dkk (2017) dengan judul "Perancangan Positioning K-Lite Radio Berdasarkan Perceptual Mapping dengan Metode Multidimensional Scaling" penelitian ini bertujuan untuk menggali persepsi para pendengar radio ketika 
mereka memilih radio bersegmen dewasa di Kota Bandung menggunakan teknik nonprobability sampling dengan cara purposive sampling. ${ }^{[3]}$

2. Penelitian yang dilakukan oleh Trinoviana (2017) dengan judul "Strategi Konvergensi Radio Sebagai Upaya Perluasan Pasar Audience dan lklan" hasil dari penelitian ini adalah ketiga radio melakukan strategi yang sama untuk memperluas khalayak yakni branding promosi, positioning, riset, dan memanfaatkan teknologi saat ini. ${ }^{[4]}$

3. Penelitian yang dilakukan oleh Anggrayni, dkk (2018) dengan judul "Analisis Strategi Komunikasi Ahli Parlimen dalam Program Siaran Interaktif di Radio Republik Indonesia dan RadioElshinta" penelitian ini bertujuan untuk menyiarkan program siaran radio interaktif, ia menjadi ruang dan peluang bagi pakar parlimen untuk menyampaikan pandangan pribadi mereka dengan menggunakan data kualitatif. ${ }^{[5]}$

4. Penelitian yang dilakukan oleh Nicolaus (2019) dengan judul "Radio as a Tool For Society Empowerment in Sub Saharan States" tujuan dari penelitian ini adalah untuk memberikan cara baru dalam pengembangan masyarakat tepatnya melalui penggunaan media massa tradisional dengan menggunakan metode marginal utilitarianisme. ${ }^{[6]}$

5. Penelitian yang dilakukan oleh Atanasov dan Pencheva, E (2016) yang berjudul "Model Aspects of Open Access to Multimedia Broadcast Services in the Evolved Packet System" tujuan dari penelitian ini adalah untuk menampilkan aplikasi pada pesan siaran dan keadaan sumber daya jaringan yang dimaksudkan untuk sesi siaran. Penelitian ini menggunakan metode multimedia broadcast. ${ }^{[7]}$

\section{HASIL DAN PEMBAHASAN}

\subsection{Preproduction}

Pre Production merupakan step atau langkah awal dimulainya suatu karya diantaranya ide, perencanaan, dan persiapan dari Konsep Produksi Media. Terdapat sepuluh langkah pre production dalam Konsep Produksi Media, dimulai dari ide yang dituangkan secara sistematis, lalu kemudian pembuatan sinopsis, narasi, storyboard, script writing, rundown, penyusunan crew, semua tahapan yang ada harus sesuai time schedule yang ditetapkan, kemudian menyusun anggaran / budget, dan peralatan yang digunakan.

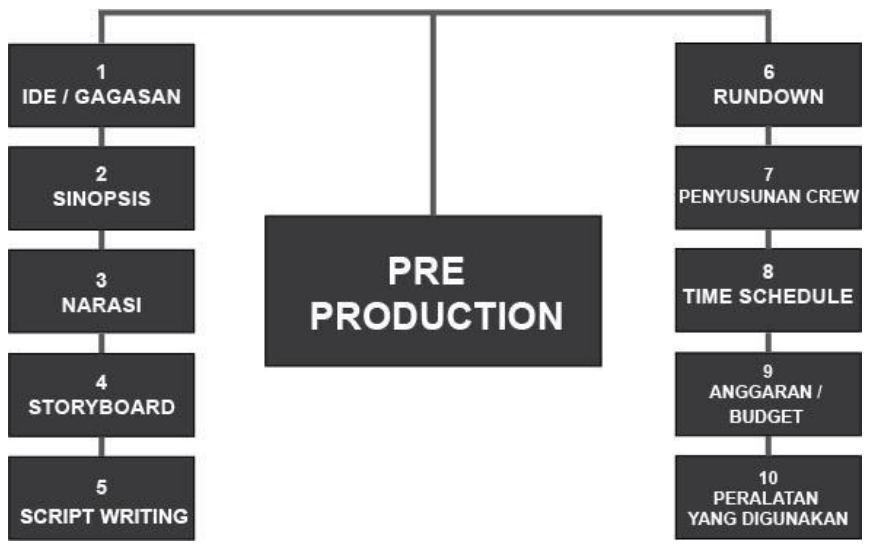

Gambar 1. Pre production 
1. Ide/Gagasan

Ide atau Gagasan merupakan sebuah rencana awal dari proses pre production, hal itu merupakan hal yang mendasar untuk perancangan sebuah karya video. Sebuah ide atau gagasan yang telah tercipta kemudian dikembangkan lagi dengan mengumpulkan data - data berdasarkan masalah yang ada. Kemudian dalam penelitian ini konsep yang dibutuhkan dalam perancangan video promosi Star Radio ini menampilkan informasi mengenai latar belakang, visi dan misi, kegiatan, serta program acara siaran pada Star Radio dengan konsep yang menarik agar dapat meningkatkan jumlah pendengar.

2. Sinopsis atau Cerita

Sinopsis merupakan sebuah ringkasan cerita video promosi, merupakan bentuk atau pendekatan dari sebuah video promosi dengan tetap memperhatikan unsur - unsur pencerminan dari sebuah video tersebut. Berikut ini adalah sinopsis dari video promosi Star Radio:

"Di awal video menampilkan bumper berupa logo Star Radio, Footage gedung Star Radio, dan profil Star Radio. Selanjutnya menampilkan video aktifitas sehari-hari, lalu menampilkan video opening penyiar program acara siaran. Selanjutnya menampilkan video sedang mendengarkan radio, request lagu lewat whatsapp, twitter, telfon dan menampilkan video hiburan. Selanjutnya menampilkan video icon Star Radio, closing penyiar program acara siaran. Dan terakhir video closing berupa bumper Star Radio, alamat, no telepon, alamat akun sosial media"

\section{Narasi}

Narasi adalah representasi dari peristiwa - peristiwa atau rangkaian dari peristiwa peristiwa. Narasi juga dapat memperjelas alur cerita dari video yang disampaikan. Berikut ini adalah naskah dubbing / voice over pada video promosi Star Radio:

"Star Radio/ mengudara sejak tanggal 11 Maret 1990// Menjadi radio yang memiliki value/ serta tempat komunikasi berinteraksi dan sosialisasi melalui program acara yang berkarakter// Star Radio memulai siaran di pagi hari yang disebut dengan Star In The Morning// Membahas seputar kegiatan sehari - hari/ seperti kehidupan berumah tangga/ persiapan beraktivitas/ olahraga/ masalah pekerjaan/ menghadirkan narasumber dari berbagai bidang/ dan juga akan diselingi oleh lagu - lagu yang hits pada masa kini// Mixing/ yang hadir dua kali setiap harinya dengan memutarkan lagu - lagu untuk menemani kamu saat sedang dijalan// Rising Star/ memberikan tips - tips yang menarik untuk para pendengarnya/ seperti gaya dalam berpakaian/ make up dan juga memberikan tips dalam memasak// Rising Star juga memberikan informasi seputar tempat makan dan informasi mengenai Kota Tangerang// Star Radio menutup hari dengan program acara siaran Portal Indonesia pada malam hari/ dalam program ini kamu juga bisa request lagu melalui chat whatsapp/ twitter/ ataupun telepon// Dan juga akan memberikan hiburan seputar challenge yang sedang viral di sosial media// Star Radio/ salah satu stasiun radio di Tangerang yang didukung dengan pendengar setia melalui 107.3 FM/ hadir sebagai radio Tangerang yang selalu menemani $\mathrm{kamu} / / "$.

\section{Storyboard}

Storyboard adalah sebuah teknik shooting management. Disini dibuat daftar pengambilan gambar pada setiap adegan, dan divisualisasikan dalam bentuk sketsa gambar atau storyboard jika diperlukan. 


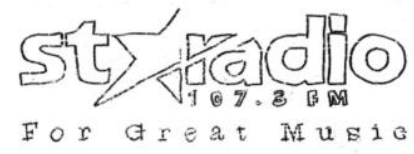

Gambar 2. Scene 1/Menampilkan video bumper logo Star Radio

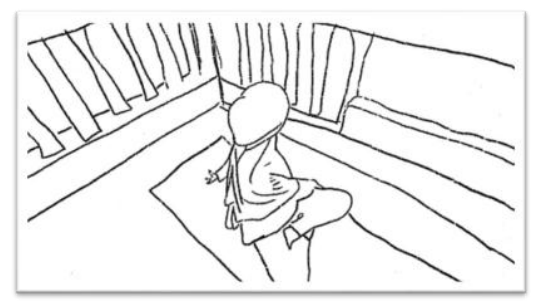

Gambar 4. EXT/ Scene 3/Day/ Medium Shot/ Menampilkan video aktivitas sehari-hari

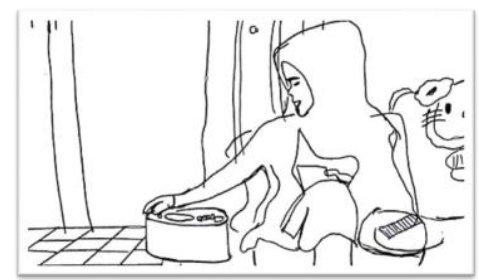

Gambar 6. INT/Scene 5/day/Medium shot/ Menampilkan video mendengarkan radio

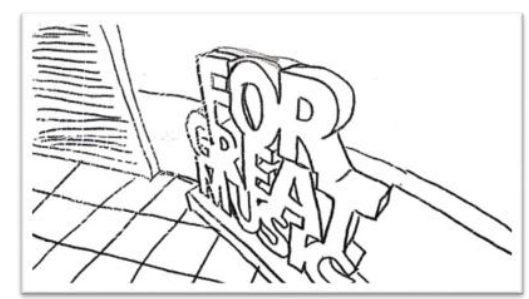

Gambar 8. INT/Scene 7/day/Close up/, menampilkan video icon Star Radio.

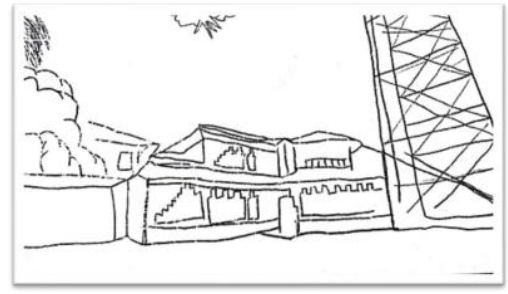

Gambar 3.INT/Scene 2/ / Day/ Medium full shot/Menampilkan video Gedung star

Radio

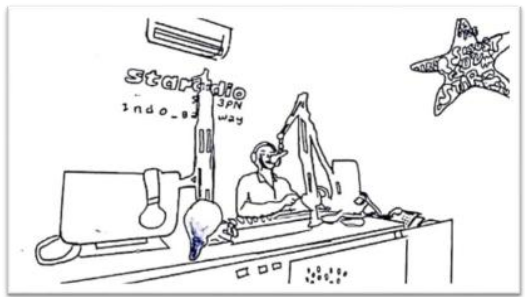

Gambar 5. EXT / Scene 4/Medium Shoot/ Menampilkan video opening penyiar

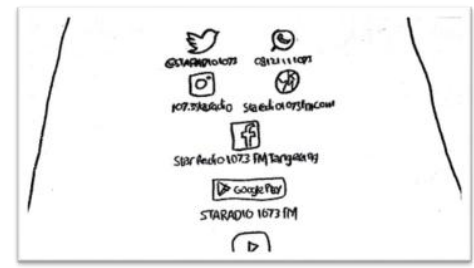

Gambar 7. Scene 6/day/Close up/ Menampilkan video request lagi lewat whatsapp, twitter dan telepon

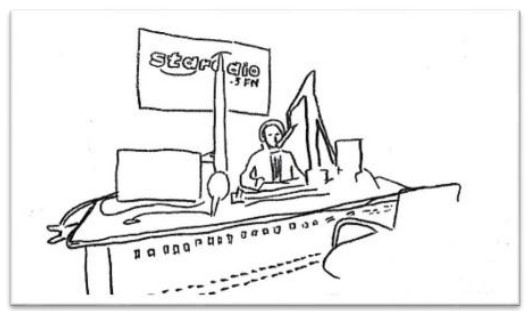

Gambar 9. INT/scene 8/day/ Medium fullshot/Menampilkan video closing program acara siaran. 


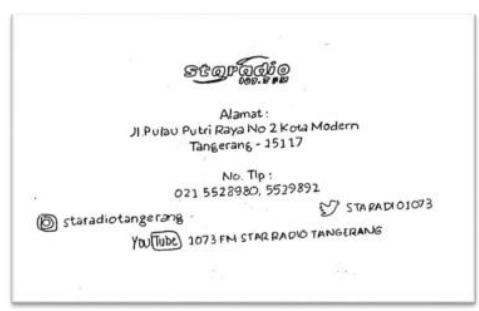

Gambar 10. scene 9/Menampilkan video closing bumper star radio, alamat, no. telepon dan alamat akun social media.

\section{Script Writing}

Script Writing dalam pembuatan video promosi program acara siaran Star Radio ini yakni gambaran alur cerita yang menarik dan detail agar mempermudah proses editing. Berikut ini tabel 1 script writing dari pembuatan video promosi program acara siaran Star Radio yaitu:

Tabel 1. Script Writing

\begin{tabular}{|c|l|l|}
\hline No. & \multicolumn{1}{|c|}{ VISUAL } & \multicolumn{1}{c|}{ AUDIO } \\
\hline 1 & $\begin{array}{l}\text { Menampilkan opening bumper logo } \\
\text { Star Radio }\end{array}$ & Music// \\
\hline 2 & Menampilkan gedung Star Radio & Music// \\
\hline 3 & $\begin{array}{l}\text { Menampilkan video aktivitas sehari - } \\
\text { hari }\end{array}$ & $\begin{array}{l}\text { Membahas seputar kegiatan sehari- } \\
\text { hari/seperti kehidupan berumah } \\
\text { tangga/ persiapan beraktivitas/ } \\
\text { olahraga/masalah pekerjaan// }\end{array}$ \\
\hline 4 & Menampilkan video opening penyiar & Music// \\
\hline 5 & $\begin{array}{l}\text { Menampilkan video mendengarkan } \\
\text { radio }\end{array}$ & $\begin{array}{l}\text { Dalam program ini kamu } \\
\text { juga bisa request lagu// }\end{array}$ \\
\hline 6 & $\begin{array}{l}\text { Menampilkan video request lagu } \\
\text { lewat } \text { whatsapp, twitter, dan telepon }\end{array}$ & $\begin{array}{l}\text { Melalui chat whatsapp/ twitter/ } \\
\text { ataupun telepon// }\end{array}$ \\
\hline 7 & Menampilkan video icon Star Radio & $\begin{array}{l}\text { Hadir sebagai radio Tangerang yang } \\
\text { selalu menemani kamu// }\end{array}$ \\
\hline 8 & $\begin{array}{l}\text { Menampilkan video closing penyiar } \\
\text { program acara siaran Portal Indonesia }\end{array}$ & Music// \\
\hline 9 & $\begin{array}{l}\text { Menampilkan video closing bumper } \\
\text { Star Radio, alamat, no telp, alamat } \\
\text { akun sosial media }\end{array}$ & Music// \\
\hline
\end{tabular}




\section{Rundown}

Rundown merupakan susunan cerita yang dirancang oleh durasi waktu. Berikut rundown dari video promosi Star Radio:

Tabel 2. Rundown

\begin{tabular}{|c|c|c|c|c|c|}
\hline No. & Scene & Location & Duration & $I N T / E X T$ & Description \\
\hline 1 & 2 & $\begin{array}{l}\text { Depan } \\
\text { gedung Star } \\
\text { Radio }\end{array}$ & $\begin{array}{l}00.00 .08- \\
00.00 .09\end{array}$ & $E X T$ & $\begin{array}{l}\text { Menampilkan } \\
\text { gedung Star Radio }\end{array}$ \\
\hline 2 & 3 & Balkon Rumah & $\begin{array}{l}00.00 .10- \\
00.00 .17\end{array}$ & $E X T$ & $\begin{array}{l}\text { Menampilkan video } \\
\text { aktifitas sehari-hari }\end{array}$ \\
\hline 3 & 4 & Ruang siaran & $\begin{array}{l}00.00 .18- \\
00.00 .28\end{array}$ & $E X T$ & $\begin{array}{l}\text { Menampilkan video } \\
\text { opening penyiar }\end{array}$ \\
\hline 4 & 5 & Kamar & $\begin{array}{l}00.00 .28- \\
00.00 .31\end{array}$ & $E X T$ & $\begin{array}{l}\text { Menampilkan video } \\
\text { mendengarkan } \\
\text { radio }\end{array}$ \\
\hline 5 & 6 & $\begin{array}{l}\text { Dalam } \\
\text { gedung Star } \\
\text { Radio }\end{array}$ & $\begin{array}{l}00.00 .31- \\
00.00 .33\end{array}$ & $I N T$ & $\begin{array}{l}\text { Menampilkan video } \\
\text { request lagu lewat } \\
\text { whatsapp, twitter, dan } \\
\text { telepon }\end{array}$ \\
\hline 6 & 7 & $\begin{array}{l}\text { Dalam Gedung } \\
\text { Star Radio }\end{array}$ & $\begin{array}{l}00.00 .33- \\
00.00 .35\end{array}$ & $I N T$ & $\begin{array}{l}\text { Menampilkan video } \\
\text { icon Star Radio }\end{array}$ \\
\hline 7 & 8 & Ruang siaran & $\begin{array}{l}00.00 .35- \\
00.00 .45\end{array}$ & $I N T$ & $\begin{array}{l}\text { Menampilkan video } \\
\text { closing penyiar } \\
\text { program acara siaran } \\
\text { Portal Indonesia }\end{array}$ \\
\hline
\end{tabular}

7. Penyusunan $\mathrm{Crew}$

Dalam Penyusunan crew, dibutuhkan ketentuan dalam memberikan jobdesk pada crew, pada sebuah perancangan video di dalam penyusunan crew terdapat Sutradara, Camera Person, Asisten Camera, Audioman, Lightingman, Editor, Script Writer, Dubber dan Pemain. Berikut adalah susunan pemain dan crew yang terlibat pada perancangan video promosi Star Radio:

Tabel 3. Susunan Crew

\begin{tabular}{|c|l|l|}
\hline No & \multicolumn{1}{|c|}{ Jabatan } & \multicolumn{1}{c|}{ Nama } \\
\hline 1. & Sutradara & Adinda Apriliani Lase \\
\hline 2. & Camera Person & Adinda Apriliani Lase \\
\hline 3. & Asisten Camera & Fahreza \\
\hline
\end{tabular}


Print ISSN: 2723-1992

Online ISSN: 2723-200X

\begin{tabular}{|c|l|l|}
\hline 4. & Audioman & Adinda Apriliani Lase \\
\hline 5. & Lightingman & Mia Permatasari \\
\hline 6. & Editor & Adinda Apriliani Lase \\
\hline 7. & Script Writer & Adinda Apriliani Lase \\
\hline 8. & Dubber & Martin \\
\hline 9. & Pemain & $\begin{array}{l}\text { Kevin, Lala, Irene, Yosho, Made, } \\
\text { Andaru, Meli, Yoga, Vida, } \\
\text { Fahrurozi. }\end{array}$ \\
\hline
\end{tabular}

\section{Time schedule}

Time Schedule merupakan alokasi waktu yang diperkirakan untuk menyelesaikan proses produksi secara keseluruhan dengan waktu yang ditetapkan. Berikut adalah time schedule perancangan video promosi Star Radio:

Tabel 4. Time Schedule

\begin{tabular}{|c|c|c|c|c|c|c|c|c|c|c|c|c|c|c|c|c|c|c|c|c|c|c|c|c|}
\hline \multirow{2}{*}{\multicolumn{2}{|c|}{ Tahapan }} & \multicolumn{4}{|c|}{$\begin{array}{c}\text { Februari } \\
2020\end{array}$} & \multirow{2}{*}{\multicolumn{4}{|c|}{$\begin{array}{c}\text { Maret } \\
2020\end{array}$}} & \multicolumn{3}{|c|}{$\begin{array}{l}\text { April } \\
2020\end{array}$} & \multicolumn{3}{|c|}{$\begin{array}{c}\text { Mei } \\
2020\end{array}$} & \multicolumn{5}{|c|}{$\begin{array}{l}\text { Juni } \\
2020\end{array}$} & \multicolumn{4}{|c|}{$\begin{array}{l}\text { Juli } \\
2020\end{array}$} \\
\hline & & 1 & 2 & 3 & 4 & & & & & 1 & \begin{tabular}{l|l}
2 & 3 \\
\end{tabular} & 34 & 1 & & 3 & 4 & 1 & 2 & 3 & 4 & 1 & 2 & 3 & 4 \\
\hline \multirow{13}{*}{ 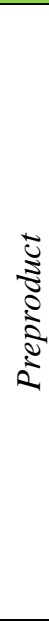 } & $\begin{array}{l}\text { Pengajuan } \\
\text { Observasi }\end{array}$ & & & & & & & & & & & & & & & & & & & & & & & \\
\hline & Pengumpulan Data & & & & & & & & & & & & & & & & & & & & & & & \\
\hline & Analisis Data & & & & & & & & & & & & & & & & & & & & & & & \\
\hline & Ide/Gagasan & & & & & & & & & & & & & & & & & & & & & & & \\
\hline & Sinopsis/Cerita & & & & & & & & & & & & & & & & & & & & & & & \\
\hline & Narasi & & & & & & & & & & & & & & & & & & & & & & & \\
\hline & $\begin{array}{l}\text { Pembuatan } \\
\text { Storyboard }\end{array}$ & & & & & & & & & & & & & & & & & & & & & & & \\
\hline & Script Writing & & & & & & & & & & & & & & & & & & & & & & & \\
\hline & Rundown & & & & & & & & & & & & & & & & & & & & & & & \\
\hline & Penyusunan Crew & & & & & & & & & & & & & & & & & & & & & & & \\
\hline & Time Schedule & & & & & & & & & & & & & & & & & & & & & & & \\
\hline & Anggaran/Budget & & & & & & & & & & & & & & & & & & & & & & & \\
\hline & $\begin{array}{l}\text { Peralatan Yang } \\
\text { Digunakan }\end{array}$ & & & & & & & & & & & & & & & & & & & & & & & \\
\hline \multirow{4}{*}{ 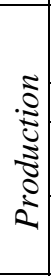 } & $\begin{array}{l}\text { Perencanaan } \\
\text { Multimedia }\end{array}$ & & & & & & & & & & & & & & & & & & & & & & & \\
\hline & Perencanaan Audio & & & & & & & & & & & & & & & & & & & & & & & \\
\hline & $\begin{array}{l}\text { Perencanaan } \\
\text { Visual }\end{array}$ & & & & & & & & & & & & & & & & & & & & & & & \\
\hline & $\begin{array}{l}\text { Perencanaan } \\
\text { Broadcasting }\end{array}$ & & & & & & & & & & & & & & & & & & & & & & & \\
\hline \multirow{6}{*}{ 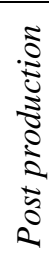 } & Digitizing & & & & & & & & & & & & & & & & & & & & & & & \\
\hline & Editing & & & & & & & & & & & & & & & & & & & & & & & \\
\hline & Mixing & & & & & & & & & & & & & & & & & & & & & & & \\
\hline & Finishing & & & & & & & & & & & & & & & & & & & & & & & \\
\hline & Tahap Keluaran & & & & & & & & & & & & & & & & & & & & & & & \\
\hline & Segmen Pasar & & & & & & & & & & & & & & & & & & & & & & & \\
\hline
\end{tabular}


9. Peralatan yang digunakan

Dalam pembuatan video promosi Star Radio ini menggunakan peralatan seperti Camera Canon 80D, Lensa Wide 10 - 18mm, Lensa Fix 50mm, Tripod, Gimbal Feiyu ak 2000, Voice Recorder Zoom hln, Microphone Rode, Memory Sandisk Ultra Extreme 64GB, LED Lighting, Drone DJI Mavic Pro, Laptop, DVD RW.

\subsection{Production}

Production merupakan tahap selanjutnya dalam konsep produksi media. Dalam proses produksi, kerjasama antara talent dan crew sangat dibutuhkan. Bahkan setiap crew dari masing - masing job desk harus menjalin kerjasama yang solid.

Dalam perancangan video promosi Star Radio, ide atau gagasan yang telah dibuat sebelumnya dimasukkan kedalam proses shooting dan perlu persiapan pada tahap produksi yang harus diperhatikan dengan baik seperti semua unsur teknis, naskah, pemain, dan sinematografi yang dijalankan sesuai dengan arahan Sutradara. Dalam menjalankan tahapan production, memerlukan tahapan perencanaan multimedia, perencanaan audio visual, dan perencanaan broadcasting.

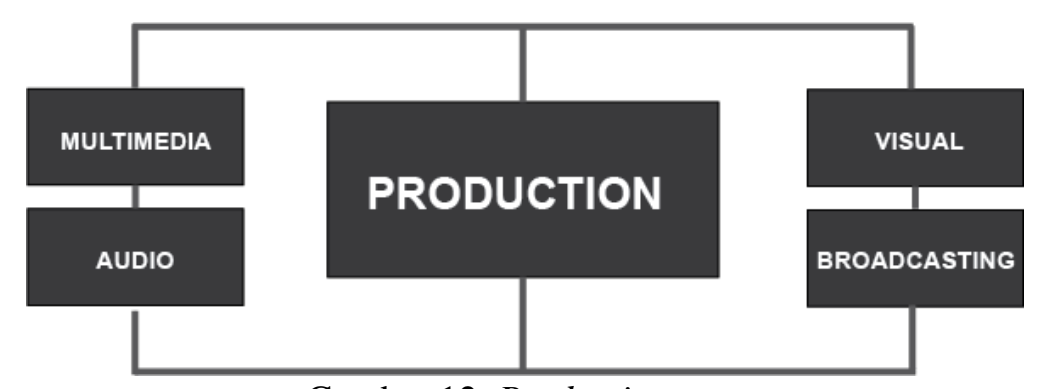

Gambar 12. Production

1. Program Visual

Berikut ini adalah tampilan isi video promosi pada Star Radio yang telah dibuat pada saat proses perancangan Konsep Produksi Media (KPM).

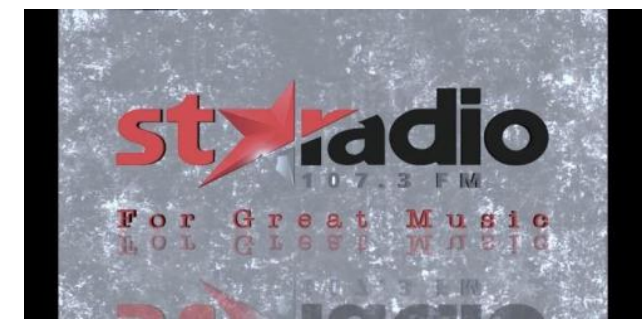

Gambar 13. Scene 1/Menampilkan video bumper logo Star Radio

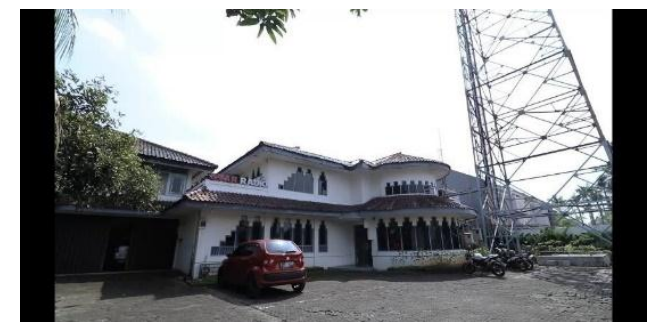

Gambar 14. INT/Scene 2/ / Day/Medium full shot/Menampilkan video Gedung Star Radio 
Print ISSN: 2723-1992

Online ISSN: 2723-200X

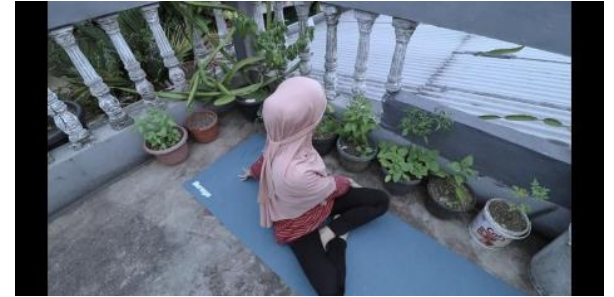

Gambar 15. EXT/ Scene 3/Day/ Medium Shot/ Menampilkan video aktivitas sehari-hari

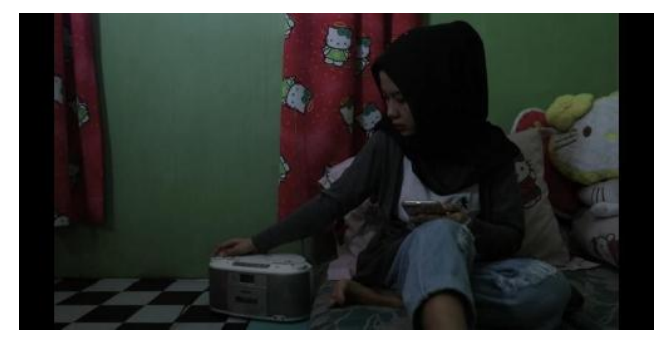

Gambar 17. INT/Scene 5/day/Medium shot/ Menampilkan video mendengarkan radio

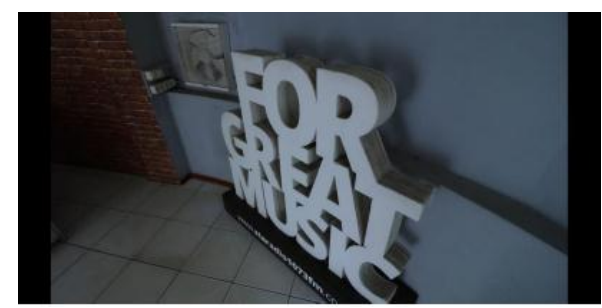

Gambar 19. INT/Scene 7/day/Close up/, menampilkan video icon Star Radio

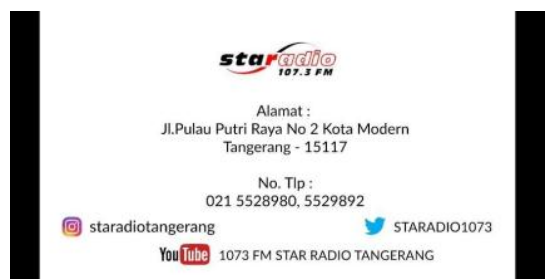

Gambar 21. scene 9/ Menampilkan video closing bumper star radio, alamat, no. telepon dan alamat akun sosial media.

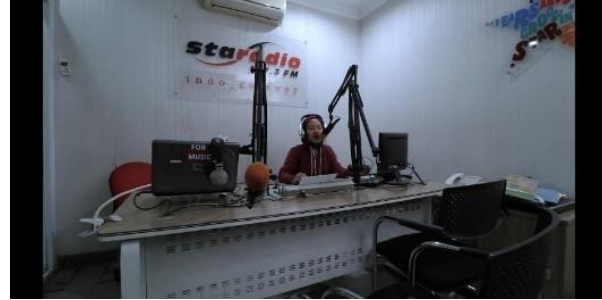

Gambar 16. EXT / Scene 4/Medium Shoot/ Menampilkan video opening penyiar

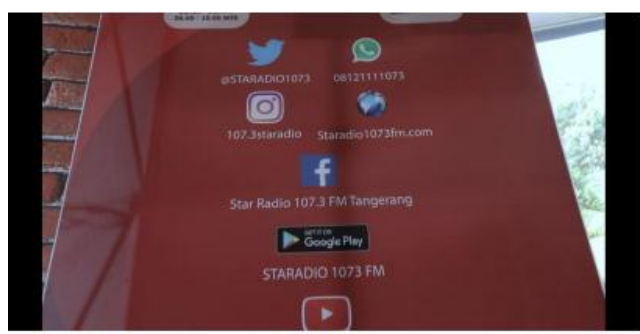

Gambar 18. Scene 6/day/Close up/ Menampilkan video request lagi lewat whatsapp, twitter dan telepon

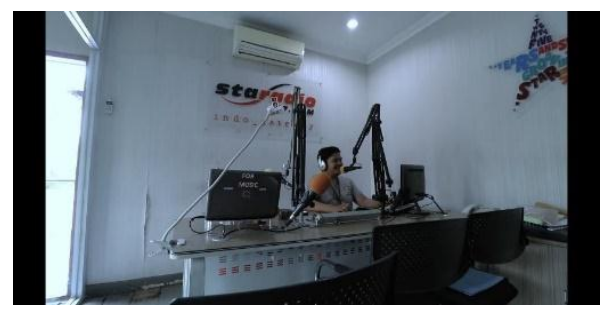

Gambar 20. INT/scene 8/day/ Medium fullshot/Menampilkan video closing program acara siaran.

\subsection{Post Production}

Post production merupakan tahapan akhir dari sebuah produksi yang sudah dikerjakan. Dimana tahapan ini adalah tahapan proses editing sebuah karya menjadi suatu video yang utuh yang siap untuk dipublikasikan. Tahapan post production selanjutnya adalah proses digitizing, editing, mixing, finishing, tahap keluaran dan segmen pasar. 


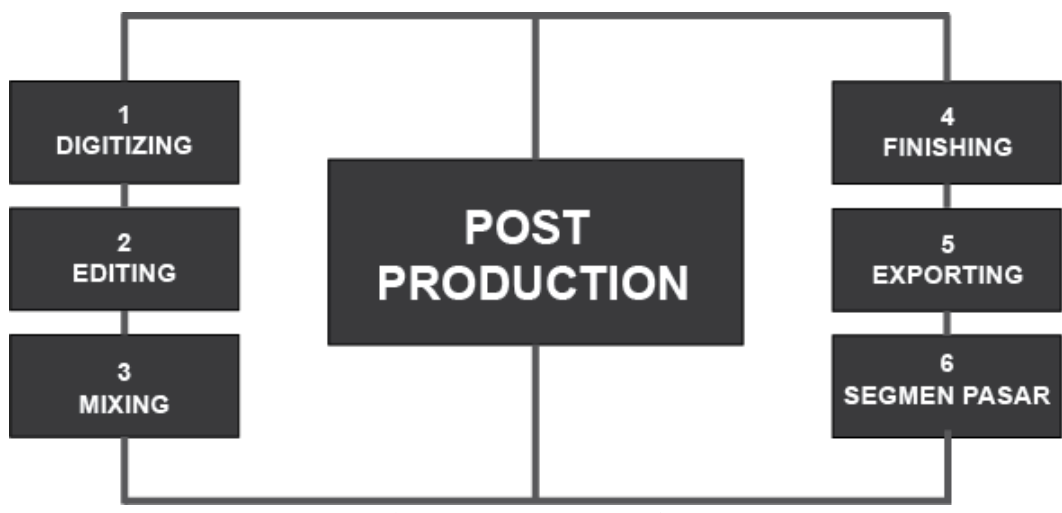

Gambar 22. Post Production

\section{Digitizing}

Tahapan Digitizing adalah tahapan proses perapihan dan pemindahan data dari kamera hasil shooting ke dalam laptop, untuk memilih pengambilan gambar dan angle yang terbaik yang akan digunakan.

\section{Editing}

Tahapan editing ini dilakukan setelah tahapan digitizing dan memerlukan waktu yang lama karena harus menyusun video dan memotong video sesuai dengan yang diinginkan untuk menghasilkan video yang utuh. Pada tahap editing ini, editor menggunakan software Adobe Premiere CC 2019, Adobe Photoshop CS6, dan Adobe Audition 2017 beberapa software pendukung lainnya.

\section{Mixing}

Mixing merupakan tahap penggabungan beberapa unsur audio visual seperti gambar, visual effect, backsound dan voice over. Dengan penggabungan ini terciptalah video promosi Star Radio yang jauh lebih menarik. Software yang digunakan yaitu Adobe Premiere Pro CC 2019, Adobe Photoshop CS6, dan Adobe Audition CC 2017.

\section{Finishing}

Pada tahap finishing, editor harus mengecek ulang agar tidak ada file video yang hilang atau rusak. Dan memastikan semua gambar, backsound, voice over dan lower third tersusun rapi dan sesuai dengan susunan Pre Production (Storyboard, Sinopsis, Narasi dan Script Writing).

\section{Exporting}

Pada tahapan exporting adalah tahap terakhir setelah proses pembuatan suatu video. Jika video sudah selesai di-render dan siap untuk di-export maka pada tahap ini adalah video yang sudah memiliki kualitas yang baik. Pada tahap exporting Video promosi Star Radio berkualitas Full HD 1920x1080 pixel dan frame rate 60 fps. Kemudian hasil render ini akan di upload ke dalam youtube dan instagram. 


\section{Segmen Pasar}

Pada tahap segmen pasar ini merupakan tahapan target pasar yang akan dituju untuk menjangkau pangsa pasar daerah Kota Tangerang, Jabodetabek dan jangkauan luas yaitu masyarakat seluruh Indonesia. Dengan adanya perancangan video promosi Star Radio ini diharapkan akan menjadi lebih menarik minat pendengar yang ingin mengetahui tentang program acara siaran serta kegiatan pada Star Radio. Dan diharapkan dengan adanya video promosi ini juga mencapai target pasar, meningkatkan persentase minat pendengar Star Radio.

\section{KESIMPULAN}

Berdasarkan penelitian yang dilakukan di Star Radio, yaitu dengan penelitian video promosi program acara siaran, yang sangat membutuhkan media informasi dalam bentuk video. Adapun beberapa point kesimpulan dari permasalahan, adalah sebagai berikut: Konsep video promosi yang dapat menarik perhatian audience yaitu dengan mengangkat program acara siaran pada Star Radio, yang berbasis audio visual, serta dilengkapi dengan music dan visual effect, sehingga tampilan video lebih menarik dan pesan yang disampaikan mudah dipahami oleh audience. Informasi yang efektif disampaikan oleh Star Radio melalui video ini yaitu meliputi latar belakang, visi dan misi, kegiatan, serta berbagai program acara siarannya, sehingga melalui video promosi ini dapat memberikan informasi yang efektif mengenai Star Radio. Serta Strategi yang dilakukan dalam memperkenalkan program acara siaran pada Star Radio ini, yaitu dengan implementasi melalui channel youtube, media sosial yaitu instagram dan ditampilkan dalam berbagai kegiatan yang ada pada Star Radio agar melalui video promosi ini, diharapkan dapat meningkatkan jumlah pendengar pada Star Radio.

\section{SARAN}

Berdasarkan hasil penelitian yang sudah disimpulkan, terdapat beberapa saran yang diberikan, yaitu sebagai berikut: Disarankan kepada Star Radio untuk terus dapat mengembangkan konsep - konsep yang kreatif dalam menginformasikan Star Radio sehingga dapat menarik perhatian audience, Disarankan kepada Star Radio untuk dapat selalu menyampaikan informasi- informasi terbaru, sesuai dengan kebutuhan dan perkembangan Star Radio, sehingga masyarakat dengan mudah memperoleh informasi dan memahami pesan yang disampaikan oleh Star Radio serta disarankan kepada Star Radio untuk terus dapat memperluas strategi penyebaran video promosi ini melalui berbagai media sosial, maupun Youtube, serta ditampilkan pada berbagai kegiatan Star Radio, sehingga banyak masyarakat yang mengenal Star Radio tersebut dan dapat meningkatkan jumlah pendengar pada Star Radio.

\section{DAFTAR PUSTAKA}

[1] Yusuf, Fachir, 2016, Analisis Proses Program Produksi Berita Radio Metro Mulawarman Samarinda, Samarinda: Universitas Mulawarman, eJournal Ilmu Komunikasi, ISSN: 2502-2597X, Vol. 4, No. 3: 99.

[2] Wiratna, Haris dan Rahmatsyam Lakoro, 2017, Penggunaan Multimedia Pembelajaran Interaktif Untuk Meningkatkan Keterampilan Menulis English simple Sentences Pada Mata Kuliah Basic Writing di STKIP Garut, Surabaya: Institut Teknologi Sepuluh Nopember (ITS), Journal Sains dan Seni ITS, ISSN: 2337-3520. Vol. 6, No. 2: 95. 
[3] Suci, Utami Winda, Yati Rohayati dan Devi Pratami, 2017, Perancangan Positioning K-Lite Radio Berdasarkan Perceptual Mapping Dengan Metode Multidimensional Scaling, Bandung: Universitas Telkom, Jurnal e-Proceeding of Engineering, ISSN: 2355-9365, Vol. 4, No. 2.

[4] Trinoviana, Anindita, 2017, Strategi Konvergensi Radio Sebagai Upaya Perluasan Pasar Audience dan Iklan, Yogyakarta: Universitas Islam Indonesia, Jurnal Komunikasi, ISSN : 2548-7647, Vol. 12, No. 1.

[5] Anggrayni, Dewi. Badrul Redzuan Abu Hassan dan Chang Peng Kee, 2018, Analisis Strategi Komunikasi Ahli Parlimen dalam Program Siaran Interaktif di Radio Republik Indonesia dan Radio Elshinta, Bangi: Universiti Kebangsaan Malaysia, Vol. 34, No. 3.

[6] Nicolaus, Widjanarko Yeremia, 2019, Radio as a Tool for Society Empowerment in Subsaharan States, Surabaya: Universitas Airlangga, Jurnal Hubungan Internasional, Vol. 12, No. 1.

[7] Atanasov, I and Pencheva, E, 2016, Model Aspects of Open Access to Multimedia Broadcast Services in the Evolved Packet System, Bulgaria: Technical University of Sofia, International Journal of Digital Multimedia Broadcasting. 